\title{
Del clero para el pueblo. La Literatura Edificante de Postguerra: un instrumento de divulgación y socialización religiosa
}

\section{La LITERATURA EdificANTE DE POSTGUERRA: El TEXTO EN SU CONTEXTO}

La finalización de la guerra civil española de 1936 dará paso a la instauración de un régimen político, liderado por el general Franco que, caracterizado como autoritario, totalitario, fascista, despótico, dictatorial o, simplemente, como franquista, tendrá como objetivo prioritario y base misma de su propia legitimación la superación del régimen anterior republicano al que se opondrá de forma sistemática. Este hecho, que a nivel ideológico -el que más nos interesa aquí por la naturaleza de nuestro objeto de estudio- ha llevado a calificar al régimen como la anti-República ${ }^{1} \mathrm{o}$ incluso a negarle cualquier personalidad en este terreno, presentándolo más como una mentalidad $^{2}$ que como un verdadero movimiento ideológico o refiriéndolo como un caso de analfabetismo ideológico ${ }^{3}$, supondrá partir, en la inmediata postguerra, de una situación conceptualizada como de anomía, de pérdida de orientación, de incapacidad para comprender la realidad por falta de modelos viables. Precisamente, este tipo de situaciones son, a menudo, como se ha señalado en diversas ocasiones, las que más directamente determinan el nacimiento de la actividad ideológica. El período de la postguerra, de esta forma, puede representarse como un amplio y magnífico proceso resocializador dentro de una vasta transformación del tipo de una alternación ${ }^{4}$. Se trata, en efecto, de una etapa que se presenta emergiendo no

1 J. Túsell, La España del siglo XX (Barcelona: Dopesa, 1975).

2 J. J. LINZ, "Una teoría del régimen autoritario. El caso de España., M. Fraga et alii (comps.), La España de los años setenta (Madrid: Moneda y Crédito, 1974), pp. 1467-1531.

3 E. Sevilla-Guzmán, M. Pérez YRlela y S. Giner, -Despotismo modemo y dominación de clase. Para una sociología del régimen franquistan, Papers, 8 (1978), pp. 103-141.

+ Véase P. L. Berger, Invitació a la Sociologia (Barcelona: Herder, 1986), cap. 3 y P. L. BERGER y T. LUCKMANN, La construcció social de la realitat (Barcelona: Herder, 1988). pp. 217 y ss. 
únicamente como un proceso de cambio, sino como un intento regenerador en profundidad. De ahí que pueda hablarse, a mi entender, para referirse a ella, de resocialización, puesto que se impone como tarea necesaria e imprescindible reasignar los significados aplicados a la realidad, lo que comportará como medida inicial el desguace y exterminio de la estructura previa que es rehusada sistemáticamente.

Pero la construcción de una nueva estructura normativa de referencia no se limita, según creo, al citado ejercicio de contraposición metódica. Contrariamente a lo que opinan los autores citados y estableciendo, por lo tanto, la pertinencia de considerar el franquismo como poseedor de una ideología propia y definida, es preciso señalar que, bajo el régimen salido de la guerra civil de 1936, se da un ejercicio complementario de revigorización y reimposición de la hegemonía religiosa del catolicismo tradicional. Este ejercicio, que no consiste tan sólo en un retorno a un ingenuo tradicionalismo, sino en una retradicionalización ideológica ${ }^{5}$, cristaliza en la expresión por excelencia de la ideología franquista: el nacionalcatolicismo.

En medio de este contexto de la postguerra al que hemos aludido esquemáticamente, con la experiencia de un pasado reciente rechazado de forma incuestionable y con la Iglesia católica asumiendola hegemonía en el plano ideológico del nuevo régimen y aportando, pues, las bases sobre las que sustentar la inevitable construcción del nuevo referente normativo que deberá difundirse ampliamente para conseguir la resocialización necesaria entre el conjunto de la población, recibirá un impulso sin precedentes la edición de un tipo de literatura, dentro de la más general de carácter religioso, que he denominado edificante.

\section{DIVULGAR Y EDIFICAR, CONSTRUIR LA REALIDAD: PARA UNA DEFINICIÓN DE LA LITERATURA EDIFICANTE DE POSTGUERRA}

Lo que distingue y da especificidad a la Literatura Edificante de Postguerra (L.E.P.) en el marco de la ingente producción y reedición de obras de carácter religioso que abundaron durante este período y que incluyen desde manuales prácticos de piedad ${ }^{6}$ hasta libros de carácter hagiográfico ${ }^{7}$, pasando por obras

\footnotetext{
5 Véase C. GEerTZ, La interpretación de las culturas (Barcelona: Gedisa, 1989), p. 191.

- Del estilo de La imitación de Cristo, de Tomás Kempis, el devocionario del Padre Vilariño, los misales de los Padres Lefevre, Ribera y Molina o las meditaciones incluidas en Jesucristo, luz del alma, de A. Ferrer o Nuevas meditaciones prácticas, del Padre Vercruysse.

7 Con colecciones específicas como -Vidas santificadas", de la editorial Castalia de Barcelona o -Bernarditan, de la editorial Difusión de Buenos Aires y títulos relativos a vidas
} 
de tipo doctrinal ${ }^{8}$, novelas de ambientación y temática religiosa ${ }^{9}$, etc., es su objetivo instructivo y divulgador.

Dicha literatura se propone, en primer lugar, vulgarizar, adaptar y difundir el mensaje emanado de los documentos de la jerarquía eclesiástica, especialmente de los producidos por la sede pontificia. Asilo reconoce explícitamente,

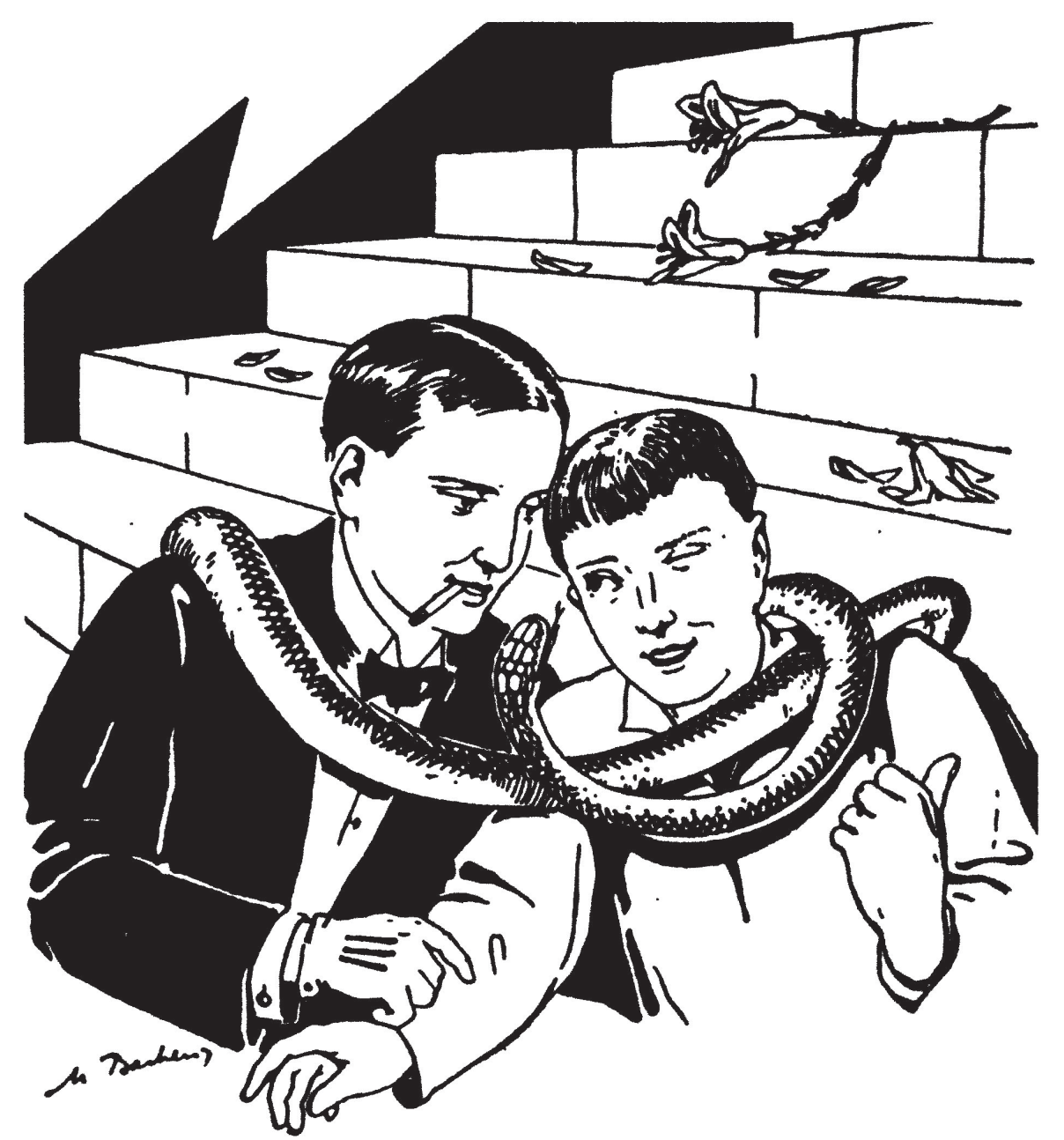

"...jPobre de la flor sobre la que viene a caer uno de estos demoledores biffalos!..."

FIG. 1.-La edificación que propone la L.E.P. es la resultante de la presentación alternativa del bien y el mal de la forma más clara y precisa. Ilustración del libro de D. Germán Jiménez, El decenio crítico (A los jóvenes de 16 a 26 años) (Bilbao-Madrid: Pía Sociedad de San Pablo, 1942), p. 56.

ejemplares, con especial presencia de historias de niñas matirizadas en defensa de su pureza, como Yo maté a Maria Goretti, de T. L. Pujadas o Josefina Vilaseca. La niña que supo defender su pureza, de J. T. Iglesias.

8 Como aquellas pertenecientes a la colección -Razonemos nuestra fen, de la Sociedad de Educación Atenas S.A. de Madrid.

9 Aquellas, por ejemplo, publicadas por la editorial Difusión de Buenos Aires en su colección :Narraciones recreativas.. 
por ejemplo, el Padre Germán Prado cuando en una de sus obras señala: «Pues estas páginas, jóvenes lectores y lectoras, no pretenden otra cosa sino divulgar las enseñanzas oficiales, descendiendo a detalles prácticos adonde no pueden bajar las Cartas Encíclicas. ${ }^{10}$. Se trata, pues, de poner al alcance del pueblo creyentela ortodoxia católica del momento, como se constata en el seguimiento fiel que se hace en las páginas de estos libros de los mensajes papales, citados textualmente en diversas ocasiones, aunque no siempre se señale explícitamente su procedencia. $\mathrm{Ni}$ que decir tiene que el gradode concordancia en los contenidos de una y otra referencia es absoluto, por el propio carácter que, como veremos, poseerán los autores de la L.E.P. y la propia vocación de este tipo de obras, si bien el hecho de moverse en un terreno formalmente no oficial (a pesar de que, lógicamente, todos los libros contarán con el inevitable sello de la censura eclesiástica o Nibil obstat y el correspondiente Imprimatur o Imprimi potest, concedido por la jerarquía eclesiástica competente) dará la posibilidad a los autores de proyectar el discurso que transmiten a los diversos aspectos de la realidad cotidiana de la época y al lugar en los que se inscriben.

Esta es, por cierto, la otra característica que define, acaso principalmente, esta literatura. No se trata pues, simplemente, de transmitir tal cual la doctrina romana, como una forma más de catequesis, como una variedad del catecismo. El objetivo es arrojar luz sobre las cuestiones y detalles del día a día que, a menudo, al ser de naturaleza profana y constituir parcelas minúsculas en relación a los grandes temas de la existencia, acaban representando el auténtico zócalo de ésta y adquiriendo, en consecuencia, una dimensión trascendente que debe ser abordada desde la perspectiva que aporta la referencia dictada por la más alta jerarquía. De esta forma se entiende, por ejemplo, que el obispo húngaro monseñor Tihamér Tóth se moleste en tratar de lo que sigue en una de sus obras:

Sea la cama más bien dura que blanda, más bien fresca que caliente. Pruébalo: cuanto más dura es la cama, con tanta más facilidad podrás dominar tu cuerpo caprichoso. [...] El calor y la cama excesivamente blanda son terribles incentivos de los deseos sexuales, que no necesitan de excitación. Ten las manos por encima de la manta, o a lo más, si durante el invierno usas doble manta, entre las dos. [...] Duerme siempre del costado derecho. No de espaldas, porque el calor de la espina dorsal excita el sistema nervioso; ni de costado izquierdo, porque así oprimes el corazón. [...] lávate después de la cintura para arriba con agua fría, y una vez enjugada, restriégate fuertemente con la palma de la mano seca. Esta gimnasia de la mañana y el uso del agua fría templa los nervios ${ }^{11}$.

10 G. PRADO, Jótenes...' Novios...! Esposos...! (Madrid: Aldecoa, 1942), p. 6.

1 T. TOTH, Pureza y Hermosura (Madrid: Sociedad de Educación Atenas, 1944), pp. $177-178$. 
Lo que se persigue, pues, es proveer un mensaje que dé una respuesta tranquilizadora a las supuestas inquietudes de los lectores, ofreciendo la posibilidad de vivir toda la existencia sin fisuras mediante el acceso a un discurso que oriente y prevenga. No es de extrañar, en este sentido, que algunas de las personas que tuvieron acceso a este tipo de literatura la identifiquen con la expresión de alibros de formación. Porque la intención pedagógica es, sin duda, uno de sus propósitos más manifiestos, como sugiere esta cita introductoria de una de las obras: "Pureza y Hermosura ha sido escrita con el más sincero deseo de iluminar vuestras cabecitas juveniles con la luz que llena el alma de verdad y alegría (...) ¡De cuántas dudas y curiosidades espero sacaros! ‘ ${ }^{12}$. Pedagogía católica, por supuesto. La información que se da, en todo caso, debe pasar necesariamente por el tamiz del referente doctrinal, de ahí su carácter eminentemente edificante. Más aún, la referencia que resulta de tal proceso no debe ser considerada como una más dentro de una pluralidad de opciones. De acuerdo con el monopolio hegemónico de definición de la realidad que desempeña la Iglesia durante el período, "Su" referencia se convierte automáticamente en «la" referencia, como bien se encarga de establecer a través de sus palabras una autora de la L.E.P.:

Querida lectora, que te encuentras al final de la obra en la que he querido ayudarte a resolver los problemas importunos, que a menudo te atormentan: he puesto bajo tus ojos las respuestas dadas a esas preguntas [...]. No he dicho sino aquello que tienes realmente la obligación de saber, pero he hablado con energía. En consecuencia, sería no solamente superfluo, sino contrario a tu interés, el escudrinar más y curiosear ciertos asuntos ${ }^{13}$.

Nos encontramos inmersos en una situación con trazos evidentes de sociedad cerrada, sin posibilidad ni conciencia de alternativas y con referentes que adquieren un carácter sagrado ${ }^{14}$. Una consecuencia de ello será que, más que un instrumento al servicio de la resolución de los problemas que acechan a sus lectores, la L.E.P. acabará desencadenando un proceso de creación de dicha problemática con el auxilio inestimable de las llamadas técnicas artificiales de acentuación de la realidad ${ }^{15}$, presentándose después como la vía necesaria para poner orden en el caos que previamente habrá contribuido a definir. Ello explica tanto la hipernormativación de la realidad que se detecta en

12 T. TOTH, op. cit., p. 7.

13 M. CSABA, La vida en flor. Lo que debe saber una joven del siglo XX (Buenos Aires: Difusión, 1945), p. 209.

14 Véase R. HORTON, El pensamiento tradicional africano y la ciencia occidental", A.A.V.V., Ciencia y brujeria (Barcelona: Anagrama, 1976), 75-117.

is Según la expresión utilizada por P. L. BERGER y T. LUCKMANN, La construcció... op. cit. 
sus páginas como el carácter axiomático de su tratamiento, que constituirá una de las principales características del discurso surgido de este proyecto, apoyado en el hecho de que se trata de un discurso revelado y, por tanto, no impugnable, si bien se da la constante necesidad de asimilar dichos principios religiosos a los de carácter natural, con lo cual las bases son a un tiempo biológicas y religiosas, lo que permite, por ejemplo, establecer una correlación entre la salud y el estado de gracia, y la enfermedad y el pecado.

Este componente binario representa la base sobre la que se ordena formal y técnicamente el discurso, configurando lo que Caro Baroja denomina una morfología del pecado a la que se opone la respectiva morfología de la virtud ${ }^{16}$. No obstante, la virtud y el pecado, el mal y el bien, aparecen en la lógica del discurso como inseparables, como las caras de una moneda y enlazando, en cierta medida, con la aproximación agustiniana al tratamiento del mal entre los hombres ${ }^{17}$. En cualquier caso el peso específico de una y otra morfología es sensiblemente distinto. En conjunto hay que señalar que el discurso de la L.E.P. presta más atención a la primera que a la segunda. De igual forma, el tratamiento que se dispensa a ambas es cualitativamente diferente. Así, para construir la morfología del pecado se utiliza como mecanismo preferente la presentación, a menudo con ribetes de un dramatismo patético rayando en el sadismo, de las consecuencias nefastas de todo orden, corporal y espiritual, a las que conduce el comportamiento descarriado. La morfología de la virtud, en cambio, acostumbra a construirse sobre la base de la consideración de diferentes personajes ejemplares ${ }^{18}$ que se convierten en modelo, se muestran como espejo, y suscitan un deseo inmediato de imitación e identificación con el héroe. En el primer caso, el carácter no institucional del mensaje de la L.E.P. permite la inclusión de referencias a otros especialistas, significativamente a médicos, cuyo dictamen hace la función como de legitimación humana que viene a sumarse a aquélla de orden moral establecida, como dando a entender que no acaba de ser totalmente suficiente.

Finalmente, los recursos utilizados para persuadir al lector se inscribirán también, con frecuencia, en un registro que se mueve alternativamente entre el paternalismo adoptado por el autor frente al lector (especialmente si aquél se dirige a un público joven $\longrightarrow$ Te tengo simpatía por tu juventud, por tu senci-

16 J. CARO BAROJA, Las formas complejas de la vida religiosa (Madrid: Sarpe, 1985), pp. 610-611.

17 Para San Agustín los malos no existian sin razón en este mundo. Pensaba que, según la voluntad de Dios, toda persona mala vive o para que se corrija o para que por ella el bueno se ejercite en el bien.

18 Como por ejemplo: Inés, Margarita María de Alacoque, Rosa de Lima, Gema Galgani, Juana de Arco, Cecilia, Lucía, Agueda, María Goretti, Antonia Messina, Emma Mariani, Josefina Vilaseca, etc. 
llez, tu generosidad, rectitud y nobleza juvenilw ${ }^{19}-$ ) y la actitud severa e intransigente que no oculta el desprecio incontenible ante hechos y personas conceptualizados como negativos por desviarse de la norma establecida -iNecio! Debieras enfermar de cuartanas, y no sientes ni el menor temblor ${ }^{20}$ -

\section{LOS AUTORES: COPISTAS SIN INGENIO}

En un tipo de literatura como el que nos ocupa, que viene a ser una especie de correa de transmisión de las consignas y principios dictados por la más alta jerarquía eclesiástica, el papel desempeñado por el autor es totalmente secundario. Su posición es habitualmente la de un simple copista, transcriptor o, en el mejor de los casos, adaptador de un mensaje que le viene ya dado y que se obliga a transmitir y difundir de forma que en el proceso no se modifique en absoluto su contenido y significación; tan solo, si acaso, se permite hacerlo más accesible al público al que va dirigido. Ello conllevará que el trabajo del autor consista, generalmente, en traducir el texto original a un lenguaje más sencillo, adornándolo o completándolo con posibles ejemplos y disquisiciones que refuercen el argumento, en aplicar su contenido a situaciones y realidades específicas y cotidianas o, a lo sumo, en realizar una labor de síntesis de diversas referencias en relación a una temática concreta. De ahí que la preocupación por las cuestiones estilísticas no sea tarea prioritaria en estos autores y así, por ejemplo, los errores ontográficos o la presencia de construcciones sintácticas incorrectas sean habituales. Asimismo, el objetivo divulgador de estas obras parece recomendar no sólo el uso de un léxico limitado y elemental, sino también el de recursos estilísticos que hagan el texto más llamativo, como parece buscar el Padre Vilarino cuando escribe: « OOh jóvenes que os metéis incautos en los placeres deshonestos! ¡Creedme! ¡Creedme! ¡Creedme! Si os metéis por ahí, tenéis que llorar mucho y padecer horriblemente. No os metáis. Deteneos. Sed castos, sed castos ${ }^{21}$. En este mismo sentido cabe interpretar, posiblemente, la presencia de ilustraciones con una imaginería sencilla y unos símbolos directos que, por ejemplo, acostumbran a representar el mal mediante una serpiente, al malo casi inevitablemente con un cigarrillo en la boca y el amor con corazones unidos con cadenas e inflamados por vigorosas llamas, aunque es preciso

19 G. PraDO, op. cit., p. 14.

20 D. G. JIMÉNEZ, El decenio crítico. (A los jóvenes de 16 a 26 años) (Bilbao-Madrid: Pía Sociedad de San Pablo, 1942), p. 165.

21 R. VIlaRIÑo, Caminos de vida. (Lecturas para Ejercicios). El baile (XLIX). La plaga de la desbonestidad (L) (Bilbao: El Mensajero del Corazón de Jesús, 1944), p. 65. 
señalar que este recurso a las imágenes es escasamente utilizado por el conjunto de obras de la L.E.P. ${ }^{22}$

Que la posición del autor dentro de la L.E.P. es irrelevante y, más aún, que su producto no merece ninguna o, en todo caso, muy escasa consideración desde un punto de vista literario lo prueban de forma concluyente hechos como los que se dan en la edición española de una obra de monseñor Tóth ${ }^{23}$, en la que, una vez traducida, se "adapta" su contenido nada menos que con la sustitución de veintitrés subtítulos de capítulo, siendo modificados ligeramente otros, adaptados algunos al carácter femenino y español e incorporando nuevos subtítulos.

Además, en el trabajo del autor de este género, como se ha apuntado, no cabe propiamente el ingenio, aunque le es dado, en ocasiones, el recurso a la fantasía, a la imaginación. De este modo no es extraño que los contenidos de partida a menudo sean llevados a extremos que pueden llegar a superar las intenciones iniciales del autor del texto de referencia.

Con estas premisas no puede sorprendernos, por previsible, la caracterización de los autores de la L.E.P. El hecho de que se trate de un tipo de literatura cuyo objetivo primordial es la transmisión de un mensaje preexistente y no la creación de un discurso original conduce a la irrelevancia del autor como creador y a la necesidad de que éste deba demostrar su competencia como transmisor cualificado. En este sentido, se valorará, ante todo, su idoneidad como garantía del contenido del libro ${ }^{24}$. Por esta razón la

22 En efecto, ya sea por el hecho de que la inclusión de ilustraciones tuviera como efecto elevar el precio de las obras en una literatura que, como se verá, se vendía a bajo precio, ya para dar a los libros una apariencia más seria, lo cierto es que son pocos los títulos que las incluyen en sus páginas, y aún aquellos que lo hacen, generalmente lo realizan de forma discreta y poco generosa, limitándolas muy a menudo al encabezamiento de los diferentes apartados. Práctica muy distinta es la que lleva a cabo la literatura referida a jóvenes martirizadas por defender su pureza, que acostumbran a incluir auténticos reportajes fotográficos, quizás a veces de dudoso gusto aunque muy posiblemente de indudable eficacia como mensajes impactantes entre las hipotéticas - y azoradas- lectoras.

23 Se trata de Pureza y Hermosura... op. cit.

${ }^{24}$ Es preciso señalar al respecto que una de las preocupaciones que se recogen en el magisterio pontificio y en el del conjunto de los representantes de la Iglesia católica de la época, siguiendo una tradición sólidamente establecida en este ámbito, y de la que, lógicamente, se hará oportuno eco la L.E.P., es precisamente la relativa a los libros malos o perversos que son condenados sistemáticamente por las citadas instancias a través, por ejemplo, de la publicación de catálogos por parte de una de las Congregaciones romanas presidida por el Papa, de obras en las que se relacionan autores y títulos permitidos y proscritos respectivamente, como la del abad Bethléem, Novelas que pueden leerse, Novelas que deben prohibirse, o la del Padre Ladrón de Guevara, Novelistas malos y 
mayoría de estos escritores posee la condición de religioso o, en todo caso, mantiene un estrecho lazo con la Iglesia, de lo cual se hace oportuna ostentación. Cuando el nombre del autor no puede ir precedido de la correspondiente indicación de su estado -Pbro., Rvdo., O.P., S.J., Emmo., obispo, abate, canónigo... - que garantice su presunta competencia y fiabilidad, se recurrirá, entonces, a la búsqueda de alguna credencial que haga las mismas funciones. Los escritores laicos, que son una minoría, necesitarán, pues, de alguna identificación suplementaria que consistirá, frecuentemente, en la mención de algún dato curricular considerado de relevancia suficiente, del estilo de "distinguido colaborador de la Revista Ave Maria" 25, "Presidenta de Acción Católica, Parroquia de Santa Cruz ${ }^{26}$ o, menos escuetamente, de una presentación personal, con un tono más bien justificativo, por parte de alguna autoridad indiscutible. Buen ejemplo de esto último lo tenemos en el prólogo redactado por monseñor Tihamér Tóth para una obra de Margarita Csaba:

Nadie, sin duda, está en mejores condiciones que la autora para tratar estos problemas, pues ella reúne en una deliciosa armonía, un amplio saber medicinal, a la experiencia de una hermana mayor, que ha frecuentado mucho a la juventud; en ella existe un equilibrio tranquilizador, que la hace apta para guiar las almas, unida a principios profundamente religiosos. Únicamente de un ambiente espiritual de esta naturaleza, lleno de distinción, podía surgir un libro de este género, moderno —en el completo sentido de la palabra - en todas sus páginas, donde cada expresión atrae e interesa; donde cada línea se ilumina, para indicar la "vían, destello de la moral cristiana ${ }^{2}$.

No es casualidad, por otro lado, que en relación al conjunto de autores laicos sean precisamente las escasas autoras existentes las que parezcan precisar de una presentación más insistente y razonada. La pasividad, la subordinación al hombre desde la reclusión en la esfera doméstica, centrando su misión en la maternidad, son los grandes pilares que sustentan el ideal femenino transmitido por la L.E.P. que, por supuesto, es también fomentado acríticamente por las mismas autoras, lo que las coloca en una situación

buenos, o de constantes disposiciones emanadas de los prelados de las distintas diócesis que aparecen recogidas en los correspondientes boletines oficiales eclesiásticos.

25 M. RIBAS, Cartas a dos novios (Barcelona: Ave María, 1947).

26 C. SAN Sebastián, Antes de casarte... (Madrid: Ediciones Studium de Cultura, 1946). Si en el caso anterior la referencia se incluía en el prólogo, en esta aparece nada menos que en la portada del libro, acompañando al nombre de la autora. Más aún, en la contraportada de la obra se incluye una breve presentación de la autora a cargo de fray Justo Pérez de Urbel, voz autorizada donde las hubiera por el hecho de desempeñar el papel de asesor nacional religioso de la Sección Femenina de Falange durante décadas.

27 M. CSABA, La vida... op. cit., pp. 7-8. 


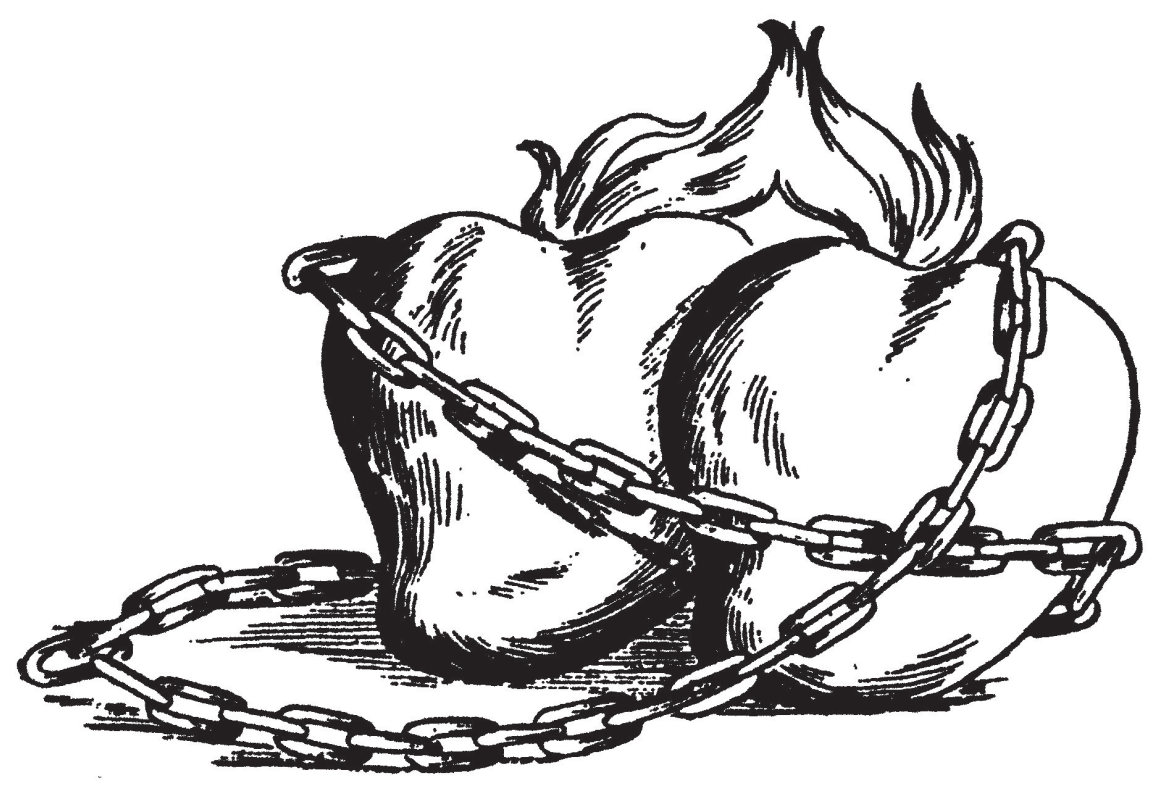

VENTAJAS DE LA INDISOLUBILIDAD DEL MATRIMONIO

FIG. 2.-Las ilustraciones son un recurso escasamente utilizado por esta literatura. Cuando, no obstante, se incorpora, se emplea una simbología elemental,sencilla y directa, como la que reproducimos del libro de M. RIBAS, Cartas a dos novios (Barcelona: Ave María, 1947), p. 79

delicada a la hora de legitimar su condición de escritoras y, por lo tanto, ante una necesidad apremiante de avaladores reconocidos.

En síntesis, queda claro que en relación a la L.E.P. no podemos hablar de una literatura de autor, lo que no es obstáculo para reconocer que, en casos muy puntuales, algunos llegaran a obtener cierto renombre, como sucede, por ejemplo, con el ya citado monseñor Tihamér Tóth, uno de los pocos que inevitablemente recuerdan quienes, un día, fueron sus lectores. El autor edificante, relegado a un segundo plano, acabará siendo inevitablemente fagocitado por el propio texto.

\section{LAS OBRAS: UNA LITERATURA PARA JÓVENES Y MUJERES}

A pesar de que uno de los rasgos que mejor definen la L.E.P. sea su carácter vocacional como intermediario del mensaje de la más alta jerarquía católica, es preciso señalar que en las páginas de esta literatura no se recoge la totalidad del referido mensaje; ni en relación a la pluralidad de sus argumentos, ni en relación a su diversidad temática. En este sentido, realizará un auténtico proceso de selección, tanto a nivel de los colectivos potenciales de lectores, como en relación a los temas tratados.

En el primer caso debe constatarse que se trata, mayoritariamente, de una literatura destinada a un público juvenil. Gran parte de los títulos y colec- 
ciones que la componen ${ }^{28}$ lo muestran de manera explícita, aunque el mayor volumen de obras va dirigido especialmente a la juventud femenina ${ }^{29}$. No parece que pudiera ser de otra manera. Tratándose de una literatura de formación, sus destinatarios privilegiados deberán ser aquellos a quienes los respectivos formadores consideren más receptivos y maleables, o más necesitados y susceptibles de formación. Y es en la juventud, de forma general, y en particular en la femenina, donde se aúnan ambos requisitos. Completando la imagen que transmite de la mujer la L.E.P., debe señalarse que entre sus atributos específicos, acaso aquel que le es reconocido como de mayor valor sea el de su "natural" inclinación y sensibilidad a la religión ${ }^{30}$. La mujer, pues, será, desde esta óptica, una buena receptora del mensaje, una buena lectora, por tanto. A su vez seguirá siendo la más indicada destinataria de esta literatura en tanto que es ella la que se erige en la demandante más procedente. Puesto que, como se establece en la base mítica del discurso en el que se inscribe la L.E.P., al haber sido ella la primera pecadora debe convertirse en primera penitente $\mathrm{y}$, por lo tanto, en la más necesitada de incentivos edificantes y formativos que le permitan expiar su culpa y alejarse de cualquier sospecha de desorden. Por otro lado, desde que a partir del siglo XVIII la mujer se convirtió en la auténtica emisaria preferente del cuerpo doctrinal de la Iglesia y en su avaladora subsidiaria ${ }^{31}$, su papel de responsable de la moralidad familiar y de la educación, especialmente religiosa, de los

28 Sirva como ejemplo, entre muchas, la colección -Eduquemos" de la Sociedad de Educación Atenas S.A. de Madrid, que incluye títulos como Formación y actuación de juventudes, de J. Maucquoi o Formación religiosa de jóvenes, de monseñor $\mathrm{T}$. Tóth.

29 Los ejemplos, por supuesto, son innumerables: colección "Muchachas" de la citada Sociedad de Educación Atenas, conteniendo obras adaptadas del prolífico monsenor Tóth como La joven de carácter, La joven creyente, La joven y Cristo, La joven de porvenir, La joven ante la vida, Pureza y Hermosura; colección "Muchacha cristiana. de las Ediciones Studium de Cultura de Madrid, con títulos como los de la serie del Padre Emilio Enciso Viana ¡Muchacha!, La muchacha en el hogar, La muchacha en el noviazgo, La muchacha en el apostolado, La muchacha en sociedad, La muchacha en la profesión; colección -Biblioteca de la joven cristiana. de la Editorial Difusión de Buenos Aires, con títulos tan reincidentes como Formación de la joven, de Baeteman, Formación religiosa y moral de la joven, de Beaudenom, Lo que debe saber una adolescente del siglo XX y Lo que debe saber una joven del siglo XX, ambos de M. Csaba, La niña de boy, de A. Bellouard o La joven prudente, de A. De Doss; etc. Todo ello sin tener en cuenta, además, la gran cantidad de títulos de la misma índole publicados sin estar incluidos en colección alguna.

30 Así por ejemplo lo dejaba entrever el canónigo F. Esteve cuando escribía: •A ti, a quien Dios concedió, tal vez como compensación de tu natural flaqueza, una feliz propensión a la fe y piedad (...), Hacia tu ideal. Unas palabras a una joven (Barcelona: Eugenio Subirana, Ed. Pontificia, 1943), p. 78.

31 Cfr. J. L. Flandrin, Orígenes de la familia moderna (Barcelona: Grijalbo, 1979), pp. $166-167$. 
hijos determina que adquiera gran importancia su preparación en este terreno, pues por ella pasa en gran medida la suerte en la reproducción del orden establecido en el mensaje religioso. En cualquier caso, las jóvenes se convierten en el destinatario más indicado de la L.E.P., al estar situadas en una posición débil, complementaria y subordinada al hombre, siendo necesario que estén vigiladas y controladas convenientemente, debiéndose asegurar su correcta socialización.

Sin duda, por este motivo, los temas recurrentes de esta literatura tendrán que ver fundamentalmente con aspectos juzgados como elementos básicos del papel que las jóvenes son llamadas a desempeñar. No es exagerado apuntar que, desde un punto de vista temático, la L.E.P. es un discurso sobre la sexualidad, como demuestra el énfasis que pone en los peligros que conlleva y la reiterada preocupación por controlarla y ordenarla según la referencia del mensaje católico. Quizás esto no sea del todo sorprendente si se considera que la construcción del género femenino se ha realizado a menudo en base a su sexualidad ${ }^{32}$ y que las nociones culturales sobre la mujer se han centrado alrededor de sus características biológicas, definiéndose casi exclusivamente en relación a sus funciones sexuales y, más en concreto, reproductoras ${ }^{33}$. Porque es esto lo que, engarzado muy a menudo en obras o capítulos que van presentando sucesivamente las diversas etapas ideales de la joven, acaba apareciendo como motivo central alrededor del cual se va configurando el mensaje transmitido por la L.E.P. El ideal de mujer que se incentiva cifra su máxima y principal realización en la maternidad, entendida en un sentido más amplio que el estrictamente biológico e incluyendo la entronización de la mujer en el ámbito doméstico como responsable de la atención del marido y los hijos y todo el conjunto de tareas del hogar. Se trata, en definitiva, de dar un mensaje que ayude a la consecución de la meta, presentada de forma compulsiva y como único camino para la mayoría, de llegar a ser una buena esposa y, sobre todo, una buena madre.

Con la maternidad como objetivo para la mujer, la literatura edificante de la época se ocupará del tratamiento de todo aquello que, de una forma u otra, se relaciona con ella. La referencia a la maternidad se utilizará como

32 Esta por ejemplo es la tesis que defienden, en relación a las sociedades mediterráneas, los representantes de la llamada Antropología del Mediterráneo. Cfr. J. G. PERISTIANY (ed.), Honour and Shame. The Values of Mediteranean Society (London: Weidenfeld and Nicolson, 1965).

33 Cfr., por ejemplo, P. CAPLAN (ed.), The Cultural Construction of Sexuality (London: Tavistock, 1987); S. ORTNER y H. WHITEHEAD (eds.), Sexual Meanings. The cultural construction of gender and sexuality (Cambridge: Cambridge University Press, 1988); M. Z. ROSALDO, "Mujer, cultura y sociedad: una visión teórica", O. HARRIS y K. YOUNG (eds.), Antropología y feminismo (Barcelona: Anagrama, 1979), 133-152. 
aglutinante para la presentación de un discurso normativo que, siendo temáticamente más amplio, procurará ceñirse a este objetivo. Por todo esto, el concepto de sexualidad que transmite la L.E.P. se equipara estrictamente con la idea de reproducción $o$, en caso de diferenciarse ambos conceptos, se produce una escisión entre ellos sin solución de continuidad. Por otra parte,

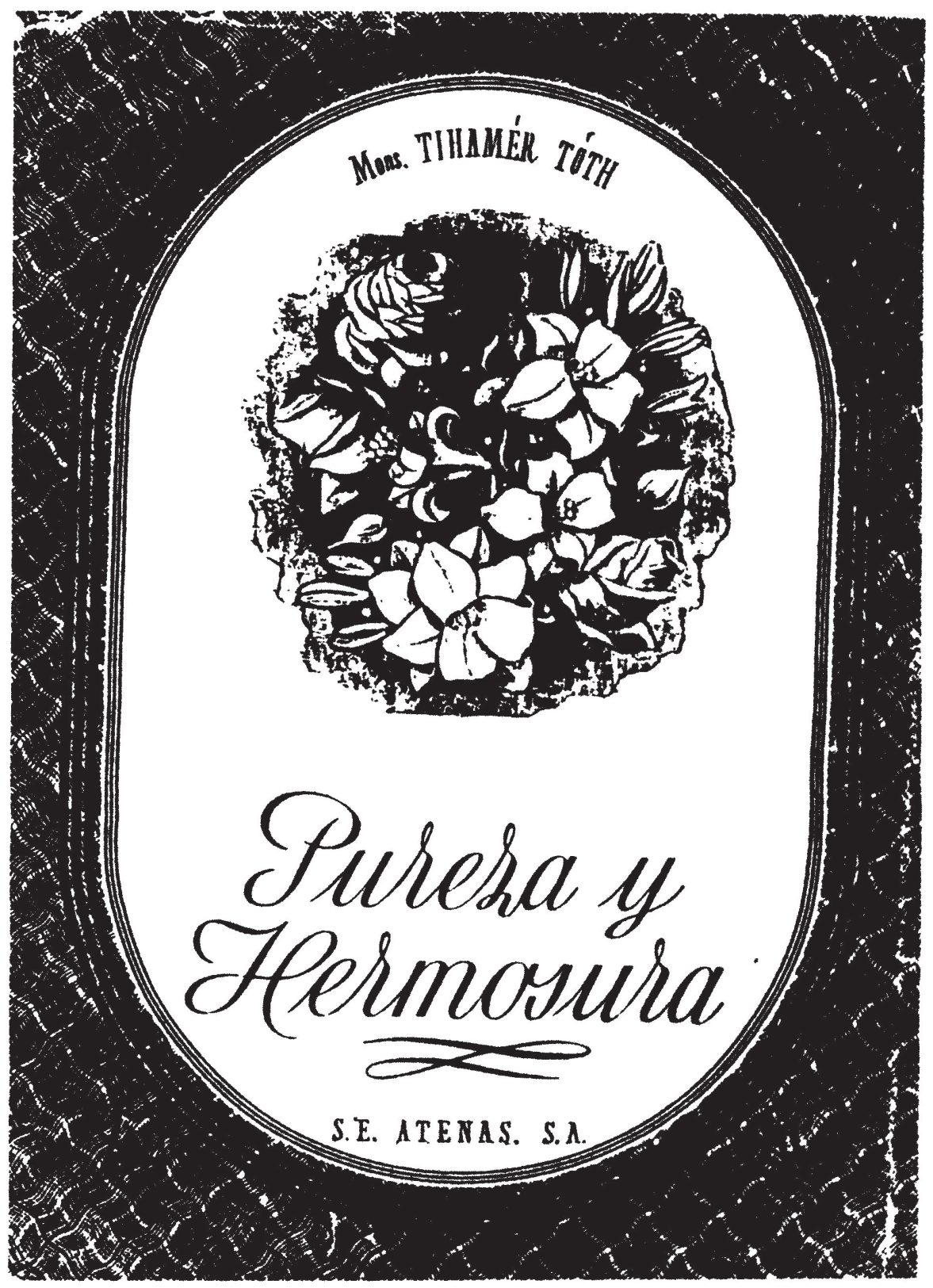

FIG. 3. - La sexualidad, ordenada exclusivamente a la función procreadora, será uno de los temas recurrentes de esta literatura. La futura maternidad debía sustentarse como garantía en la pureza, difícil pero hermosa, de la juventud, como trata de establecer el libro de uno de los autores más prolíficos y de mayor éxito de esta literatura, el húngaro monseñor Tihamér TOTH, cuya portada de la edición española se reproduce: Pureza y Hermosura (Madrid: Sociedad de Educación Atenas, 1944). 
de este ideal de maternidad, resultante de esta sexualidad reducida a la procreación, la única que se legitima en el seno del sacramento del matrimonio, se hará derivar la definición misma de la feminidad, sirviendo como punto de referencia para elucubrar sobre las características de la mujer. En cualquier caso, delimitado con claridad el objetivo vital femenino, buena parte de las obras se centrarán más en desmenuzar y atender las instancias previas, conducentes al citado objetivo, que en el tratamiento directo del mismo. Por

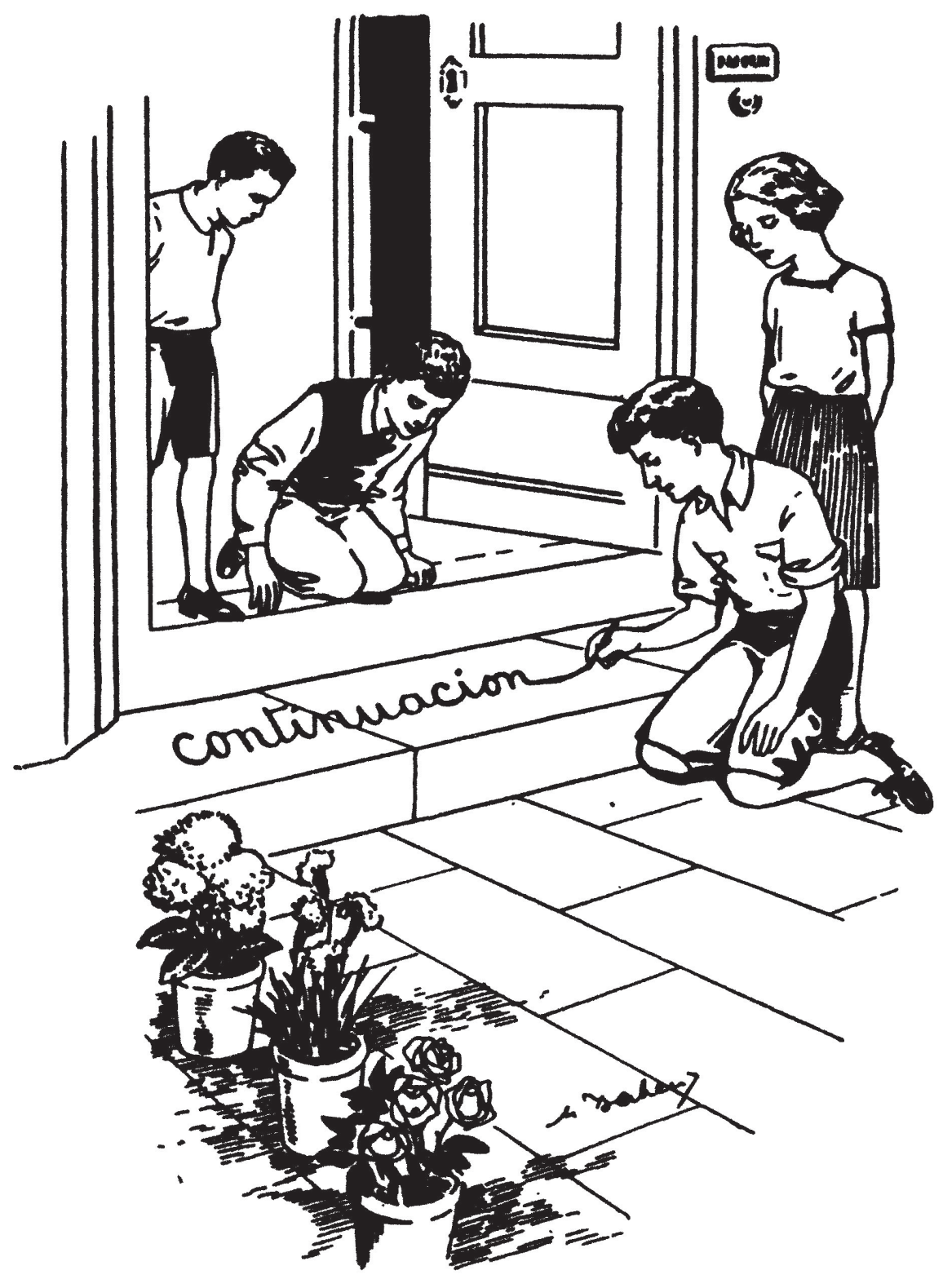

-...juera miras egoista, pensando en que tu casa se va a inundar de criaturas!...

FIG. 4.-El matrimonio y la formación de una familia numerosa es el ideal vital normativo que transmite como meta para la mayoría la L.E.P. Ilustración del libro de D. Germán JIMÉNEZ, El decenio crítico ( $A$ los jóvenes de 16 a 26 años) (Bilbao-Madrid: Pía Sociedad de San Pablo, 1942), p. 245. 
esta razón no son pocas las páginas que se dedican a abordar temáticas tan distintas como la pureza-impureza, el vestuario, el baño, la playa, la gimnasia, el deporte, la elección de novio-a, las relaciones con el otro y los otros, la amistad, el control de la natalidad, el trabajo extradoméstico, etc., que en última instancia tienen que ver, según los autores, con la aspiración de ser madre. Porque, aunque sea tan solo a modo de ejemplo, únicamente la pureza absoluta - que a menudo acaba comportando la adopción de una actitud de terror y desconfianza para con el propio cuerpo y el contacto y la relación con los demás, desde los amigos al novio-, sobre todo previa al matrimonio, es garantía segura de la no transmisión de una herencia luctuosa a los futuros hijos. Asimismo pensando en ellos, podrán tratarse temas como el de la gimnasia y el deporte en la mujer -importantes para la futura salud de la descendencia-; la necesidad de elegir bien al futuro cónyuge, atendiendo a cuestiones relacionadas con su salud, necesariamente perfecta en vistas a la futura tarea procreadora, el grado de parentesco, por igual motivo, o su estatus moral, que obligaría a buscar un consorte de probada religiosidad como garantía de una descendencia prolífica de acuerdo con los cánones establecidos por el discurso que analizamos; o la condena de toda práctica anticonceptiva, contraria a la realización del ideal de la mujermadre ${ }^{34}$, o de la misma realización de un trabajo extradoméstico por parte de la madre, que necesariamente sería perjudicial, no tanto para ella como para sus hijos, durante el embarazo y posteriormente en el período de crianza.

En síntesis, pues, la L.E.P. conforma un discurso acerca del papel ideal asociado a la mujer desde la perspectiva oficial eclesiástica, centrado en su función esencial de madre y estructurado alrededor de las diversas etapas del ciclo vital normativo estipulado para ésta, como sintetiza el título de una de sus innumerables obras, concretamente la del benedictino Germán Prado: Jóvenes...! Novios...! Esposos...! ${ }^{35}$

34 El ideal de la maternidad vigente en la época y defendido por el referente católico era, ante todo, el de la matemidad prolífica. En este sentido, tanto o más que la calidad de los hijos y de la función maternal, perseguida a través de las consideraciones reseñadas anteriormente, se busca la cantidad, en consonancia con el ideario de la política pronatalista del régimen. El cardenal-arzobispo de Toledo y Primado de España, Isidro Gomá, no podía ser más explícito al respecto cuando apuntaba: “(..) cuanto más fecundas, más madres (...), La Familia segün el derecho natural y cristiano (Barcelona: Rafael Casulleras, 1946), p. 194.

35 Op. cit. Que el punto de llegada y episodio vital fundamental, por tanto, lo constituye la maternidad dentro del matrimonio lo prueba bien claramente la misma extensión de los capítulos del citado libro: mientras que el primero, dedicado a la juventud, ocupa 50 páginas y el segundo, relativo al noviazgo, tan sólo 36, el tercero y último, en donde se trata del matrimonio, supera ampliamente la extensión de ambos, con un total de 134 páginas. 


\section{LA DIFUSIÓN: LECTORES Y LECTURA}

Caracterizada hasta aquí la que hemos llamado Literatura Edificante de Postguerra, parece oportuno plantearse aún algunas cuestiones relevantes, si se quiere de carácter indirecto, relacionadas con la misma. Entre otras, y siendo posible agruparlas bajo el epígrafe genérico de la difusión, no ocupan, sin duda, un lugar menor las que se refieren al volumen de la producción de libros de esta literatura, a las tiradas y número de ediciones, a sus canales de difusión y publicidad, al prototipo de comprador-lector, al índice de lectura... Cuestiones, ciertamente, fundamentales, cuya respuesta debe hacer posible un conocimiento más profundo y preciso de la L.E.P. y del contexto en el que se inscribe. Cuestiones, no obstante, que no siempre se pueden responder satisfactoriamente, de acuerdo con la información de que disponemos, y a las que sólo podemos aproximarnos para completar en lo posible la comprensión de la literatura edificante.

Si bien existen algunos datos, más o menos fiables, referidos al volumen de ejemplares editados de las numerosas publicaciones periódicas de la época, que indican la importancia de esta prensa ${ }^{36}$ y cuya extrapolación a la vertiente bibliográfica parece del todo pertinente por representar una dimensión más del mismo fenómeno, no tenemos cifras orientativas sobre la edición de libros. Es cierto que el número de colecciones y editoriales

36 La Guía de la Iglesia en España 1955 da una lista, que reconoce incompleta, de unas mil publicaciones, mientras que la Oficina Estadística de la Iglesia, en su estudio de 1957 La prensa de la Iglesia en España, clasifica un total de 847 revistas y la Guía correspondiente al año 1960 reseña 1603 títulos. El Anuario de la Prensa Española 1965, editado por la Dirección General de Prensa, computa, por su parte, 458 publicaciones religiosas. La obligatoriedad del depósito legal, establecida en 1957, del que carecían, sin duda, muchas revistas religiosas de escaso alcance, como premisa para aparecer en el citado anuario puede explicar esta disminución del volumen total. En relación a otros aspectos de esta misma índole cabe señalar que la mayoría de estas revistas tenía un carácter mensual, cuando no superior, con tiradas que difícilmente superaban los 500 ejemplares. A pesar de esto, algunas superaron con creces los 10.000, como consta en alguna de las fuentes estadísticas citadas. Es el caso de las editadas por la Compañía de Jesús: De Bromas y de Veras (12.000), El Mensajero del Corazón de Jesús (110.000), El Promotor de la Devoción de la Sagrada Familia (148.000); Ecclesia (17.000), de Acción Católica, y Alba (12.000), de las jóvenes de esta misma asociación; las revistas de propaganda misional: Anales de la Santa Infancia (72.000), Enfermos misioneros (20.000); y otras como Reinado Social del Corazón de Jesús (90.000), de los Padres de los Sagrados Corazones, o El Mensajero de San Antonio (50.000), franciscana, a las que habría de sumarse, como se ha dicho, un innumerable conjunto de pequeñas publicaciones, a veces de fugaz existencia, de colegios religiosos y congregaciones, santuarios, centros provinciales de Acción Católica, propaganda devocional diversa, investigación teológica, escriturística y canónica, etc. Cfr. R. GOMFZ, Política y Religión en el régimen de Franco (Barcelona: Dopesa, 1976). 
específicas destinadas a este tipo de literatura constituye un indicador de su alcance. Constatada, pues, la proliferación de títulos, es más difícil precisar su volumen de edición. En este punto, no parece que la realidad fuera sensiblemente distinta de la que se ha apuntado para las publicaciones periódicas. Así, junto a títulos de tirada e incidencia escasas, aparecen otros a los que no es arriesgado suponer un éxito de ventas. En este sentido, el número de ediciones puede ser un buen indicador del itinerario comercial de algunas obras de la L.E.P. Las reediciones no parecen ser raras, siendo habitual, cuando menos, la existencia de dos o tres ediciones para un buen número de obras ${ }^{37}$. En cualquier caso, parece fuera de toda duda que durante esta época las ediciones y reediciones de este tipo de literatura fueron considerablemente superiores a las de años anteriores ${ }^{38}$.

En cuanto a las vías de promoción y difusión no puede sorprender que sea a través de los canales que ofrece la estructura eclesiástica por donde se publicite e, incluso, se distribuya mayormente esta literatura. Las páginas de los distintos Boletines Oficiales de las respectivas diócesis, obispados o arzobispados, están plagadas de recomendaciones explícitas de obras de este tipo ${ }^{39}$. Más aún, la propia jerarquía eclesiástica restableció, después de haber

$37 \quad$ Así pues, junto a obras que a duras penas conseguirán una edición limitada y una escasa difusión, también podemos encontrarnos con algunas que constituirán un auténtico éxito de ventas. La L.E.P., por consiguiente, contará con sus respectivos "best-sellers", identificables básicamente por el número de ediciones que alcanzarán $y$, aunque más difícil de precisar, por el volumen de la tirada de los mismos. Un buen ejemplo de este último caso lo representan la mayoría de los libros escritos por el inefable monseñor húngaro Tihamér Tóth, que con su obra Joven de carácter alcanzó, al menos, doce ediciones. En cuanto al volumen de estas ediciones no parece que, de entrada, fuera excesivo, si bien un inicial éxito de ventas podía disparar el alcance de las sucesivas ediciones, como hacen suponer, aunque se trate de uno de los escasos ejemplos aislados de los que hemos podido obtener información al respecto, las cifras relativas al libro de Jesús Urteaga, autor de un precedente éxito con El valor divino de lo bumano, Dios y los bijos (Madrid: Rialp), que en menos de un año alcanzó más de los 100.000 ejemplares según la siguiente serie: $1 .^{2}$ edición: noviembre de 1960 (4.000 ejemplares), $2^{2}{ }^{2}$ edición: diciembre de 1960 (6.000), 3..$^{2}$ edición: diciembre de 1960 (4.000), 4. ${ }^{2}$ edición: enero de 1961 (20.000), 5.² edición: octubre de 1961 (70.000).

38 Una buena muestra de ello la tenemos en la trayectoria seguida a este respecto por el libro del cardenal I. GOMÁ, La Familia... op. cit., editado inicialmente en mayo de 1926. La segunda edición saldrá a la luz en febrero de 1931, mientras que la tercera deberá esperar hasta agosto de 1940. Por contra, a partir de este momento, las reediciones se sucederán a un ritmo muy superior: en junio de 1942 aparece la cuarta edición y en 1946 la quinta.

39 Sirva de ejemplo, entre muchos, la referencia aparecida en el Boletín Oficial del Arzobispado de Tarragona, núm. 36, de 18 de Enero de 1946, pp. 567-568, del libro de monseñor Tihamér Tóth Se sobrio. Después de aportar con todo detalle las informaciones 
sido creada aen tiempos de lucha y persecución " ${ }^{40}$, durante la postguerra para el conjunto del Estado Español la celebración del llamado "Día de la Prensa Católicar. La jomada, organizada anualmente el 29 de junio, festividad de San Pedro, y dirigida en especial a los curas párrocos, consistía en una colecta destinada *a favorecer con ayuda económica a las publicaciones de propaganda religiosa que necesitan esta ayuda; a adquirir y repartir en la mayor profusión posible, folletos, hojas, libros de instrucción, en hospitales, asilos, prisiones y otras entidades; ayuda a bibliotecas parroquiales y de Asociaciones de Apostolado, etc. etc. ${ }^{41}$. Se trataba, pues, de un día especialmente indicado para sensibilizar a los feligreses, informarles, recomendarles y, en definitiva, controlar su acceso a la lectura. Por si ello no fuera suficiente,las múltiples prácticas públicas piadosas que proliferaron durante la postguerra o el contacto mantenido con los fieles a través de las diversas actividades de Acción Católica, como los Círculos de Estudios,hacían posible que el cura párroco, el predicador de ejercicios espirituales o de alguna fiesta señalada o el sacerdote conferenciante de algún acto público pudieran completar la tarea publicitaria. Cuando, además, toda esta ofensiva había conseguido finalmente dar sus frutos, el feligrés, convertido en lector, recibía un nuevo estímulo publicitario desdelas propias obras con las que había empezado a familiarizarse. La preocupación de la Iglesia del momento por establecer nítidamente la separación entre literatura buena y mala será recogida dócilmente por los autores de la L.E.P., que incluirán muy a menudo en sus obras de formación generosos apartados dedicados al tema, cosa que suponía la condena de la literatura considerada perversa y una recomendación, explicitada sin rubor, de la literatura identificada como buena y saludable. Este procesode retroalimentación llevado a cabo por las obras edificantes de la época se completará con frecuencia de forma más directa a través de diversas estrategias publicitarias como la inclusión, en las primeras o últimas páginas de los libros, de referencias a otras obras, especialmente a las de la misma colección, de las que incluso llega a incluirse una breve reseña ${ }^{42}$.

relativas a la editorial, el traductor, la casa distribuidora, el número de páginas, las medidas del libro, el tipo de portada, la caja, el cuerpo, el precio, etc., pueden leerse en la reseña de la obra párrafos como el que sigue: -Recomendamos con todo calor Se sobrio no solamente a los jóvenes sino acaso más a los padres y educadores (...) creemos que la mejor terapéutica moral es presentarles (a los jóvenes) este libro, que es una verdadera escuela de carácter.

40 Boletín Oficial Eclesiástico del Arzobispado de Tarragona, núm. 96, 15 de junio de 1950 , p. 1090.

41 Idem., p. 1091.

42 En este sentido, completando también aquella premisa imprescindible a la que aludíamos de legitimación del autor de la obra, algunos libros de la L.E.P. destacan en sus 
Garantizado el conocimiento de la existencia de esta "buena literatura" a través de las prácticas reseñadas, no parece que las facilidadespara hacerse con algunos de los títulos fueran menores que las apuntadas para su difusión publicitaria. En primer lugar, es oportuno señalar sobre el precio de estas obras, lógicamente variable en función de la calidad de edición, la extensión, la inclusión o no de ilustraciones, etc., quese trata, en general, de una literatura al alcance de la mayoría. Los precios oscilaban entre las seis y las veinticinco pesetas, situándose de media sobre las diez pesetas. El lector, además, contaba con todas las facilidades para adquirir estas obras en librerías especializadas, donde era práctica corriente aceptar la compra a crédito, o, en los pueblos, donde no existían, la alternativa era la venta-exposición de libros que se hacía regularmente en beneficio de las misiones, con motivo de la fiestadel libro, del aludido día de la prensa católica o de las distintas prácticas públicas de piedad en las que se quería dar respuesta inmediataal deseo, que ellas mismas habrían contribuído a suscitar, de comprar estos libros por parte del público. $\mathrm{Si}$, a pesar de todo, estas vías no eran suficientes para permitir el acceso a la literatura de formación, el lector interesado contaba aún con otros medios: la existencia de bibliotecas ambulantes, llamadas populares, que visitaban regularmente las distintas parroquias, ofreciendo un servicio de préstamo bibliotecario olas propias bibliotecas parroquiales estables garantizaban sobradamentedicha comunicación. Tampoco era raro el intercambio de obras entre lectores, especialmente entre los miembros de las diversas ramas de Acción Católica.

Precisamente la referencia a este colectivo nos conduce a la consideración de algunas de las cuestiones que nos planteábamos al inicio de este apartado y que tienen que ver, conocida la naturaleza de la oferta y la difusión de la L.E.P., con las características de sus destinatarios y su incidencia. El prototipo de comprador, mejor que lector, de esta literatura lo constituirá el individuo alineado de manera activa e incondicional al lado de la Iglesia. Ciertamente, no podía ser de otro modo: los títulos son inequívocos, los contenidos claros y explícitos, los autores y las vías de promoción y difusión

mismas páginas de presentación algunas de las supuestas virtudes que lo avalan con mayor crédito si cabe. Ejemplos de esto son, entre otros muchos, el libro del abad J. B. ChautARD, El alma de todo Apostolado (San Sebastián: Pax, 1941), en cuya primera página puede leerse: OBRA RECOMENDADA POR MUCHOS PRELADOS. Es utilísima a los EJERCTTANTES (eclesiásticos y religiosos), a los SEMINARISTAS, a los NOVICIOS y demás PERSONAS consagradas al Apostolado; el del también abad C. Grimaud, Futuros esposos (Madrid: Sociedad de Educación Atenas, 1942), en donde se indica que LLa Academia Francesa le adjudicó en 1923 el premio Montyon, y en 1929 el premio Fabien;; o el del cardenal I. GOMÁ, La Familia... op. cit. en cuya última página se incluyen algunos párrafos extraídos de las críticas de periódicos y revistas relativas al libro en cuestión. 
claramente asociados a la Iglesia. Los mismos autores, en ocasiones, delimitando de forma más precisa el colectivo genérico al que se dirigen, formado, como se ha visto, por jóvenes y mujeres principalmente, caracterizan de manera explícita a los auténticos destinatarios de su mensaje:

¡Oh jóvenes de mi corazón! A vosotros hablo, no a todos, a vosotros los que no habéis corrompido aún vuestros cuerpos, santificados por el bautismo que os incorporó a Jesucristo, el hijo de la Virgen. ¡Oh jóvenes de mi corazón, los que aún sois castos! ${ }^{43}$

Nos encontramos, pues, ante una literatura que no pretende tanto servir de instrumento de conversión para un lector descarriado, irrecuperable, sino más bien ir al encuentro de un público que, inmerso en una estrategia más amplia de socialización dirigida por la Iglesia, se encuentra totalmente predispuesto a la recepción del mensaje que transmite la L.E.P. Se trata de un público necesitado de instrumentos de edificación que le ayuden a alcanzar el ideal de perfección cristiana. De ahí que hable, no por casualidad, de literatura edificante.

Pero si el lector de la L.E.P. solo busca asentar y pulir su vivencia en la fe, el acuerdo y la conformidad cada vez mayores entre el ideal de vida cristiano y su comportamiento cotidiano ${ }^{44}$, bien puede ocurrir que el instrumento utilizado, constituido en símbolo de este deseo de perfección, acabe representándolo. Entonces, el libro adquiere propiamente un carácter simbólico, aparece como un objeto mágico, investido de un valor y un podér que confieren a su propietario la parcela del saber que el libro, como un depósito sagrado, contiene. Comprar uno de estos libros significa, pues, adquirir las normas y los principios que incorporan. Es una manifestación explícita de conformidad con ellos. Prestarlo o regalarlo ${ }^{45}$, aún más: no sólo se proclama la identificación de quien lo regala con el contenido sino que, en buena

43. R. VIlaRiño, Caminos de... op. cit., p. 40.

${ }_{44}$ Quizás por estas razones resulta característico de esta literatura, como se ha apuntado, buscar, a menudo obsesivamente, el peligro por doquier, incluso en los lugares, actos o personas más insospechados y aparentemente inocuos, así como ocuparse de la práctica totalidad de los aspectos, incluidos los supuestamente más intrascendentes, que conforman la vida diaria de las personas.

45 Ya se ha señalado el carácter habitual del préstamo de libros entre lectores. Habría que añadir a ello la práctica que hemos podido constatar, a través de algunas dedicatorias que aparecen en algunos de los libros de bibliotecas devotas familiares a las que hemos podido acceder y de la información proporcionada por sus propietarios, que se producía entre personas pertenecientes a la Acción Católica de regalarse libros de este tipo con motivo del cumpleaños u onomástica del novio, la novia o el cónyuge, o como símbolo de consideración a alguna persona. 
medida, supone un mensaje inequívoco para quien lo recibe. Quien ha adquirido previamente la virtud, y la posee, la transmite a otro realizando toda una declaración de principios e intenciones en la que, tras situarse a sí mismo, declara los límites entre los cuales desea encontrar a aquél. Qué duda cabe que en medio de un contexto como el de la postguerra, en el que la relación entre jóvenes de distinto sexo era problematizada de raíz y fuertemente controlada, cuando no proscrita, este tipo de práctica podía suponer un beneficio psicológico importante como descarga de la angustia que el trato con el otro podía suscitar. El libro edificante, pues, manifestaba, en un contexto de dominio hegemónico de la religión como único referente normativo válido, y de una religión predominantemente pública, la adscripción del comprador-poseedor del mismo dentro de los límites del orden, actuando a su vez como un potente símbolo de condensación semántica allí donde no era dado conducirse con libertad.

Quizás por todo esto, en última instancia, los indicadores respecto a la difusión de esta literatura edificante poco o nada tengan que ver con el índice real de lectura ${ }^{46}$. Comprar libros, retenerlos, intercambiarlos, regalarlos... no es garantía ni sinónimo de leerlos. Menos aún cuando el libro, como ocurre en este caso, posee otros valores que incluso superan al del propio contenido. Menos aún cuando el lector prototípico ya "conoce" sus contenidos. Por ello no es de extrañar que muchas de las páginas que integran la L.E.P. quedaran

46 Esta literatura edificante que analizo - quizás sea momento de señalarlo ya-mantiene evidentes puntos de contacto con otros fenómenos similares pertenecientes a otras épocas y lugares. Concretamente, para esta cuestión de la que se habla, es interesante señalar que algunos estudiosos de la llamada "Bibliothèque Bleuew de Troyes, aparecida a partir del siglo XVII en Francia, con una vocación fundamentalmente popular, han destacado el hecho, en principio contradictorio, de su extraordinaria difusión entre una masa de población mayoritariamente analfabeta. Es una explicación de la índole de la que hemos ensayado para nuestro caso, es decir, que considere al libro como un objeto simbólico ante todo, la que permite precisamente a los citados autores explicarse el éxito de dicha literatura. Salvando, lógicamente, las distancias, esta hipótesis no sólo puede servir para aplicarla al caso que estudiamos en relación a la importancia simbólica del libro, sino también, en cierta medida, para explicar asimismo la difusión de la L.E.P. en aquellas zonas de España con una lengua materna propia distinta del castellano, única lengua utilizada por la L.E.P., y con una parte importante de población con dificultades evidentes para comprenderlo fácilmente, e incluso para el conjunto del Estado Español, con una tasa de analfabetismo funcional presumiblemente bastante elevada durante este periodo. Para un análisis de la literatura perteneciente a la "Bibliothèque Bleue*, cuyo paralelismo con la L.E.P. sugiere una fecunda posibilidad comparativa que se constata, por ejemplo, en la idoneidad de aplicación indiscriminada de algunas de las hipótesis que hemos utilizado tanto en uno como en otro tipo de literatura, puede verse, especialmente, G. Bolleme, La Bibliotbèque Bleue (Paris: Gallimard/Julliard, 1971) y L. ANDRIEs et alii., La -Bibliothèque Bleue nel Seicento o della letteratura per il popolo (Bari-Paris: Adriatica/Nizet, 1981). 
sin leer, como lo prueba que algunos de los libros que hemos podido consultar en diversas bibliotecas devotas particulares tuvieran todavía sus páginas unidas por sus extremos. El libro, de hecho, ya había cumplido su función.

\section{UN INSTRUMENTO DE TRANSMISIÓN, UNA LITERATURA PARA EL PUEBLO}

El razonamiento anterior nos conduce directamente a una de las características fundamentales para identificar la L.E.P., que presentaremos ahora, de forma sintetizada, acompañada de un breve intento de valoración de la misma.

Efectivamente, más que el hecho de que las páginas de estos libros edificantes fueran leídas - que lo fueron, sin duda-, lo verdaderamente relevante es que fueran escritas. Porque lo fueron, como es obvio, en un contexto preciso, con una finalidad específica, bajo unos presupuestos determinados. La L.E.P. forma parte de un vasto y potente proceso resocializador que se da en el Estado Español durante el período de postguerra. No se trata, no obstante, de un fenómeno exclusivamente español. Entre las obras de la L.E.P. las hay de autores españoles, pero también, y de forma importante, de franceses, húngaros, italianos, alemanes, etc. Quizás sí sea específicamente española su espectacular difusión, y la manera como se produce, en un período concreto como el de la postguerra. En esencia, debe inscribirse en un marco general, el del mundo católico correspondiente a la etapa preconciliar, especialmente a los papados de Pío XI y Pío XII. En este sentido, los contenidos de la literatura de edificación, directamente inspirados en el mensaje de la jerarquía de la época, vienen a representar, en buena medida, una de las últimas expresiones del catolicismo de signo más tradicional previa a la renovación del Concilio Vaticano II. En muchos países en los que esta literatura proliferó vino a coincidir, además, con la emergencia de ideologías y regímenes políticos de signo autoritario y conservador. El caso español tal vez sea, en este sentido, el más paradigmático, puesto que ambas tendencias no solo coincidirán en el tiempo sino que, además, realizarán una perfecta simbiosis en el marco del nacionalcatolicismo, que se consolidará y perdurará por un período de tiempo sensiblemente más dilatado.

De ahí precisamente proviene la significación específica que alcanza la L.E.P.. Porque en el contexto preciso de la postguerra española aparece como un instrumento más en el proceso de difusión del aparato normativo que, a su vez, es definido hegemónicamente por la Iglesia. Como herramienta de transmisión, hemos podido calificarla de literatura de divulgación y caracterizar a sus autores de meros copistas o transcriptores. Si bien es cierto de forma general, no puede olvidarse el hecho de que en la difusión, por 
mediatizada que esté por el contenido de referencia, también se produce alguna transformación del mensaje. Así pues, en la escrupulosa tarea de trasladar el mensaje de la jerarquía al pueblo fiel, los autores edificantes modificarán en alguna medida su contenido, enfatizando algunos temas, silenciando otros, o dando un tratamiento susceptible de alguna interpretación ligeramente matizada de la ortodoxia. La transmisión, consecuentemente, no es neutra, sino que incluye un conjunto de prácticas de selección y privilegio de los contenidos de referencia que atenúa, simplifica, olvida o incorpora significados. A pesar de ello, el carácter mimético de la L.E.P. es indiscutible. Ambas dimensiones, de todas formas, le otorgan su auténtica fisonomía y le confieren su verdadero valor.

Porque el valor de la L.E.P., como ya ha quedado claro, no es, ciertamente, de carácter literario. Su valor radica, a mi entender, en que constituye una fuente inapreciable, y de las más fecundas, para intentar el análisis del nivel de difusión de la estructura normativa y para penetrar en la espina dorsal de dicha estructura ${ }^{47}$. La L.E.P. nos acerca tanto al nivel de la producción normativa como al de su gestión o difusión. En relación al primero no tanto porque dicho nivel sea su fundamento único y natural que ella se encargará de traducir y transmitir y del cual, en consecuencia, nos está hablando contínuamente, sino, más aún, porque al realizar una selección de los diversos temas que agrupa este nivel nos estará revelando lo significativo del mismo, lo que se considera como prioritario y que, por tanto, debe tratarse para llevarlo al conocimiento de sus lectores. En cuanto al segundo, su consideración es obvia: si algo define a esta literatura por encima de cualquier otra característica, es su vocación divulgativa. Nos encontramos, pues, frente a una vía privilegiada de acceso al discurso normativo dominante en su fase de difusión. Se trata de uno de los escasos y más directos canales que poseemos para conocer de qué manera era transmitido el mensaje proviniente de las referencias oficiales. Siendo difícil el acceso al contenido real, literal, de sermones, cursillos, confesiones, conferencias... y tantas otras

47 Aunque siempre es discutible declarar aquello que tiene o no tiene valor como objeto de estudio, me parece fuera de toda duda el interés de esta literatura en relación a los temas y las dimensiones señalados. En este sentido no encuentro especialmente acertada la opinión de M. T. Gallego cuando, en su por otro lado excelente estudio, afirma refiriéndose al contenido - tan próximo al de la L.E.P. - de los discursos de los asesores religiosos de la Sección Femenina que: ofrecen un nulo interés para su utilización como material de estudio. Producen, en cambio, irritación intelectual. Sin embargo, conviene transcribir alguno de ellos para mostrar cuáles eran los contenidos del discurso dirigido a las mujeres. (Mujer, Falange y Franquismo, Madrid, Taurus: 1983. p. 147). O poca importancia se otorga al análisis del discurso dirigido a las mujeres o acaba confundiéndose el objeto de estudio de la ciencia con la propia ciencia. En ambos casos, lamentablemente, mucho me temo que acaba haciéndose un flaco favor a ésta. 
prácticas donde se llevaba a cabo la difusión de la referencia normativa, esta literatura viene a representar, por su misma naturaleza, la aproximación más cercana a las citadas prácticas. Y no solo eso, la L.E.P. puede proporcionar un valor superior al de instrumento especialmente asequible de transmisión normativa. Porque en alguna ocasión sus obras, a buen seguro, sirvieron de guía y de referencia directa a más de un especialista en la gestión de la norma. De este modo, solo con que alguno de estos especialistas - sacerdotes, maestros, padres,...-, principales agentes y responsables directos del proceso de socialización, tuviera conocimiento de ella, el mensaje quedaba asegurado a la práctica totalidad del público al que aspiraba a llegar.

¿Cuál era en realidad este público? La comunidad cristiana, especialmente la creyente-practicante, la más comprometida con el mensaje eclesiástico; no en vano se trata de una literatura edificante, si bien todo parece indicar que jóvenes y mujeres configurarían los colectivos preferidos como destinatarios de la L.E.P.. Los autores, además, debían pensar en un público popular. Estamos hablando de una literatura que declara como uno de sus objetivos preferentes la divulgación de las directrices eclesiásticas, popularizándolas, acercándolas a la comprensión de personas que, presumiblemente, alcanzarían con dificultad a conocerlas e interiorizarlas sin la ayuda de estos instrumentos de difusión de los que forma parte la L.E.P. Su público está alejado por igual de los sectores más instruidos de la sociedad y de los analfabetos reales o funcionales. A los primeros, posiblemente, la lectura de estas obras les hubiera producido un cierto sonrojo y vergüenza intelectuales. Los segundos, no obstante, pudieron convertirse en sus compradores por el valor simbólico de estos libros.

En síntesis, podemos concluir intentando definir la L.E.P. atendiendo a las clásicas preguntas de Lasswell —quién dice qué, a quién, por qué medio y con qué efectos-. Así, la Literatura Edificante de Postguerra constituiría un instrumento de socialización religiosa, dirigido a jóvenes y mujeres vinculados a la Iglesia, cuyo objetivo principal es la divulgación del discurso oficial de la jerarquía de la época. A nivel temático, pone especial atención en el tratamiento de la sexualidad asociada a la reproducción en el seno de la familia cristiana y en la organización de la vida cotidiana del lector como un ejercicio edificante en búsqueda del ideal de perfección. Los autores, que tienen un papel secundario, son principalmente religiosos. En definitiva, la L.E.P., representa una de las últimas ofensivas, especialmente potente y duradera en España, del discurso tradicional católico previa al Concilio Vaticano II. 
El artículo se ocupa del análisis de la que hemos denominado Literatura Edificante de Postguerra (L.E.P.). Se trata de un tipo de producción literaria específica dentro de la más amplia de carácter religioso, caracterizada por su objetivo divulgador del discurso oficial de la jerarquía eclesiástica de la época. Precisamente, la referencia temporal que se incluye en la denominación de esta literatura se justifica por el hecho de que ésta se inscribe, como un elemento más, en el contexto de la ofensiva socializadora del catolicismo tradicional que se dará, de forma especialmente destacada y duradera, durante la postguerra española. A pesar de ello, se trata de un fenómeno no exclusivamente español, como lo prueba la numerosa presencia de autores de diversos países del mundo católico occidental. Los autores, por cierto, poca consideración obtendrán en una literatura que se define como instrumento al servicio de la transmisión de un mensaje. El mensaje, a su vez, focalizará su atención en la sexualidad orientada a la procreación, por lo que no puede sorprender que se trate de una literatura dirigida especialmente a las mujeres y a los jóvenes, que serán, pues, sus principales lectores o, mejor dicho, compradores, puesto que por sus características peculiares la L.E.P. acabará constituyéndose en un potente símbolo de identificación y comunicación.

The article deals with the analysis of what we have previously called Literatura Edificante de Postguerra. (Postwar Ennobling Literature). It is a type of specific literary production, part of a broader are of religious character, characterized by its objective of spreading the official speech of the church hierarchy of that time. Precisely, the historical reference included in the name of this literature, is justified by the fact that it lies within the context of a socializing offensive of the traditional catholicism which will take place, during the spanish potswar period in a tangible and lasting form. Nevertheless, we are dealing with a fact which is not exclusively spanish as it can be seen in the works of the great number of authors from other western catholic countries. The authors, by the way, will get little consideration from a literature defined as an instrument in the service of the transmission of a message. In its turn, the message will focus its attention on a procreation orientated sexuality, and therefore it is not surprising, that it is a literature particularly addressed to women and youth who are going to be its main readers or, better said, buyers. The special features of the L.E.P. will finally be a strong symbol of identification and communication. 